\title{
COLLABORATIVE GOVERNANCE DALAM PENGEMBANGAN DESA WISATA
}

\author{
Ardhia Mafaza dan Kristina Setyowati \\ FISIP Universitas Sebelas Maret Surakarta
}

\begin{abstract}
In order to develop a Tourism Village in the Borobudur Area, the Government through the Ministry of State Owned Enterprises established the Village Economic Center Program (Balkondes) in the Borobudur Area. This study aims to identify the collaborative governance process in the Village Economic Center Program (Balkondes) in Borobudur Village, Magelang Regency. The research method employed was qualitative one with descriptive approach. Sampling technique employed was purposive sampling one. Techniques of collecting data used were interview, observation, and documentation. Technique of analyzing data used Miles and Huberman's data analysis technique. The result of research showed that collabo-rative governance among stakeholders in the Village Economic Center Program (Balkondes) in Borobudur Village, Magelang Regency has been going well, which is marked by the stakeholders having carried out their main tasks optimally based on the eight indicators of collaboration from De Seve. However, related to administrative entities in a cooperation agreement only regulates between PT. Taman Wisata Borobudur, Prambanan \& Ratu Boko (PT. TWC) as assistant SOE and sponsors, and Borobudur Village Government through village-owned business entity (BUMDes), have not explained the involvement of PT. CBT Nusantara Management (PT. MCN) as the manager of the Balkondes Program. So that boundary and exclusivity in governance have not mentioned all parties involved in collaboration.
\end{abstract}

\begin{abstract}
Abstrak: Dalam rangka mengembangkan Desa Wisata di Kawasan Borobudur, pemerintah melalui Kementerian Badan Usaha Milik Negara membentuk Program Balai Ekonomi Desa (Balkondes) di Kawasan Borobudur. Penelitian ini bertujuan untuk mengindetifikasi adanya proses collaborative governance dalam Program Balai Ekonomi Desa (Balkondes) di Desa Borobudur Kabupaten Magelang. Metode penelitian yang digunakan adalah penelitian kualitatif dengan pendekatan deskriptif. Penentuan sampel dengan teknik purposive sampling. Teknik pengumpulan data menggunakan wawancara, observasi dan dokumentasi. Teknik analisis data menggunakan teknik analisis data Miles and Huberman. Hasil penelitian menunjukan bahwa collaborative governance diantara para stakeholder dalam Program Balai Ekonomi Desa (Balkondes) di Desa Borobudur Kabupaten Magelang sudah berjalan dengan baik yang ditandai dengan para stakeholder sudah menjalankan tugas pokoknya secara maksimal berdasarkan 8 indikator kolaborasi dari De seve. Hanya saja terkait entitas administratif dalam perjanjian kerjasama hanya mengatur antara PT. Taman Wisata Candi Borobudur, Prambanan \& Ratu Boko (PT. TWC) selaku BUMN pendamping dan sponsor, dan Pemerintah Desa Borobudur melalui Badan Usaha Milik Desa (BUMDes), belum menjelaskan terkait keterlibatan PT. Manajemen CBT Nusantara (PT. MCN) yang sekarang selaku pengelola Program Balkondes. Sehingga boundary dan exclusivity dalam governance belum menyebutkan semua pihak yang terlibat dalam kolaborasi.
\end{abstract}

Kata kunci: collaborative governance, pengembangan desa wisata, Program Balkondes

\section{PENDAHULUAN}

Sebagai destinasi utama, Candi Borobudur tentu menjadi magnet wisatawan, baik wisatawan lokal maupun wisatawan internasional. Akan tetapi diketahui bahwa keberadaan Candi Borobudur belum mampu mendongkrak kesejahteraan masyarakat lokal yang tinggal di sekitar kawasan Candi Borobudur. Berdasarkan berita yang dimuat dalam www.antarafoto.com, diketahui bahwa keberadaan dan pertumbuhan desa wisata di Kecamatan Borobudur belum bisa maksimal karena selama ini kunjungan wisa- tawan cenderung masih terkonsentrasi di Candi Borobudur (Kurniawan, 2017). Sejalan dengan masalah belum berkembangnya desa wisata di Kecamatan Borobudur Kabupaten Magelang, pemerintah melalui Kementerian Badan Usaha Milik Negara (BUMN) membentuk Program Balai Ekonomi Desa (Balkondes) sebagai peran aktif Badan Usaha Milik Negara (BUMN) dalam mendorong kemajuan ekonomi masyarakat. Program Balai Ekonomi Desa (Balkondes) merupakan Program Sinergi "BUMN Hadir Untuk Negeri" sebagai bentuk tanggung jawab 
sosial perusahaan dengan ketentuan yang diatur dalam Undang-Undang Republik Indonesia Nomor 40 Tahun 2007 tentang Perseroan Terbatas, yang di dalamnya mengatur ketentuan tentang Tanggung Jawab Sosial dan Lingkungan serta Peraturan Menteri Badan Usaha Milik Negara Nomor PER-09/MBU/07/2015 tentang Program Kemitraan dan Program Bina Lingkungan Badan Usaha Milik Negara (BUMN).

Balkondes akan dimanfaatkan sebagai sebuah etalase bagi perekonomian daerah, yang mana Balkondes akan memberikan ruang bagi pemerintah desa maupun masyarakat desa untuk mengembangkan potensi ekonomi yang ada di desa. Balkondes dibangun dalam bentuk bangunan berupa balai dan homestay. Melalui Balkondes, masyarakat desa akan dipersiapkan untuk menyambut serta memberikan pelayanan maksimal bagi para wisatawan yang datang ke daerahnya sehingga Balkondes menjadi sebuah bentuk dukungan untuk menggenjot kunjungan wisatawan di Indonesia. Peningkatan jumlah kunjungan wisatawan ini diharapkan akan memberikan dampak positif pada perbaikan ekonomi masyarakat sekitar, sehingga kesejahteraan masyarakat meningkat (www.balkondes.borobudur. com).

Program Balkondes ini pertama kali dilaksanakan di kawasan borobudur, Kabupaten Magelang karena berdasarkan data dari Kementerian Pariwisata Republik Indonesia, Borobudur merupakan salah satu Destinasi Pariwisata Prioritas (DPP) yang mendapatkan perhatian khusus dari Kementerian Pariwisata melakukan pengembangan desa wisata dengan Program Balkondes.

Balkondes di Kecamatan Borobudur dibangun atas inisiasi dari salah satu BUMN yaitu PT. Taman Wisata Candi Borobudur, Prambanan, dan Ratu Boko (PT.TWC). Dalam pembangunan Balkondes ini didampingi oleh beberapa BUMN pendamping dan BUMN sponsor. BUMN pendamping adalah BUMN yang akan mendampingi seluruh Balkondes di Kecamatan Borobudur dari tahap pembangunan sampai tahap operasional. Selanjutnya yang dimaksud dengan BUMN sponsor adalah setiap satu BUMN akan memberikan kontribusinya kepada satu desa wisata yang mana setiap BUMN sponsor akan mengeluarkan dana Corporate Social Responbility (CSR) untuk pembangunan Balkondes.

BUMN pendamping dalam Program Balkondes Borobudur adalah PT. Indonesia Tourism Development Corporation (PT. ITDC), PT. Taman wisata Candi Borobudur, Prambanan, dan Ratu Boko (PT. TWC) dan PT. Patra Jasa. Pembangunan Balkondes di Kecamatan Borobudur sudah dimulai sejak Tahun 2016 lalu, dengan didampingi oleh PT. Taman wisata Candi Borobudur, Prambanan, dan RatuBoko(PT.TWC) dalam perencanaan pembangunan (beberapa dibangun swakelola BUMN sponsor dan sebagian dititipkan TWC untuk dibangunkan). Selanjutnya pada awal tahun 2018 terdapat serah terima Operasional Balkondes dari PT. Taman wisata Candi Borobudur, Prambanan, dan Ratu Boko (PT. TWC) kepada PT. Patra Jasa. Kemudian, berdasarkan hasil pra survey dalam penelitian ini, pada Bulan April 2019, terjadi transformasi dari PT. Patra Jasa kepada PT. Manajemen CBT Nusantara (PT. MCN) sebagai pendampingan dalam pengelolaan Program Balkondes. Hal tersebut berarti bahwa, saat ini PT. Manajemen CBT Nusantara (PT. MCN) yang melakukan pendampingan dalam pengelolaan Program Balkondes bersama-sama dengan pemerintah desa dan masyarakat desa.

Selain BUMN Pendamping, juga terdapat 20 BUMN sponsor dalam Program Balkondes di Kecamatan Borobudur. Hal ini dikarenakan terdapat 20 desa wisata di Kecamatan Borobodur. BUMN sponsor dalam Program Balkondes di kawasan Borobudur adalah PT. Taman Wisata Candi Borobudur, Prambanan dan Ratu Boko (PT. TWC), PT. Bank Negara Indonesia, PT. Pertamina, PT. Perusahaan gas Negara, PT. Bank Tabungan Negara, PT. Patra Jasa, PT. Perusahaan Listrik Negara (PT. PLN), PT. Jasa Raharja, PT. Semen Indonesia, PT. Telekomunikasi Indonesia, PT. Hutama Karya, PT. Jasa Marga, PT. Bank Madiri, PT. Angkasa Pura I, PT. Pembangunan Perumahan (PT. PP), PT. Bank Rakyat Indonesia, PT. Angkasa Pura II, PT. Perkebunan Nusantara III, PT. Pegadaian, dan PT. Pupuk Indonesia. 
Penelitian ini fokus pada kolaborasi antar stakeholder yang terlibat secara langsung dalam Program Balkondes di Desa Borobudur atau yang sering disebut dengan Balkondes Warung Kopi Borobudur yang mana Balkondes Warung Kopi Borobudur merupakan Balkondes percontohan atau pilot project dari seluruh Balkondes di Kecamatan Borobudur. Kolaborasi yang terjalin adalah antara PT. Taman Wisata Candi Borobudur, Prambanan \& Ratu Boko (PT. TWC), PT. Manajemen CBT Nusantara (PT. MCN), Pemerintah Desa Borobudur, BUMDEs Graha Mandala Borobudur, karyawan Balkondes Borobudur, dan masyarakat Desa Borobudur.

\section{METODE}

Penelitian ini merupakan penelitian deskriptif kualitatif yang dilaksanakan di Balai Ekonomi Desa (Balkondes) Borobudur atau Balkondes Warung Kopi Borobudur yang berada di Desa Borobudur, Kecamatan Borobudur, Kabupaten Magelang, Jawa Tengah. Penelitian ini menggunakan teknik penentuan informan purposive sampling. Stakeholder atau pihak yang terlibat dalam pengembangan desa wisata melalui Program Balkondes. Pengumpulan data adalah dengan wawancara mendalam, observasi dan dokumentasi. Uji validitas data menggunakan triangulasi teknik. Sedangkan analisis data dilakukan dengan teknik analisis interaktif Miles dan Huberman meliputi reduksi data, sajian data, dan penarikan kesimpulan.

\section{HASIL DAN PEMBAHASAN \\ Proses Collaborative Governance dalam Pengembangan Desa Wisata}

Dalam mengembangkan desa wisata melalui Program Balkondes Borobudur ini, tidak bisa berjalan sendiri, akan tetapi perlu suatu kolaborasi dari berbagai pihak seperti BUMN dalam hal ini PT. Taman Wisata Candi Borobudur, Prambanan \& Ratu Boko (PT.TWC) dan PT. Manajemen CBT Nusantara (PT. MCN), Pemerintah Desa Borobudur, BUMDes Borobudur yaitu BUMDes Graha Mandala, karyawan Balkondes, dan masyarakat Desa Borobudur sendiri.
Proses kolaborasi dalam pengembangan desa wisata melalui Program Balkondes Borobudur memiliki beberapa tahapan antara lain:

a. Perjanjian Kerjasama antara BUMN sponsor dengan Pemerintah Desa

Kerjasama yang dilakukan diawali dengan permintaan dari Pemerintah Desa Borobudur agar PT. Taman Wisata Candi Borobudur, Prambanan \& Ratu Boko (PT. TWC) mau membangunkan Balkondes di Desa Borobudur.

b. Pembangunan Balkondes Warung Kopi Borobudur

PT. Taman Wisata Candi Borobudur, Prambanan \& Ratu Boko (PT. TWC) dengan Pemerintah Desa Borobudur telah melaksanakan pembangunan Balkondes secara baik. Beberapa hal yang telah dilaksanakan oleh kedua belah pihak berdasarkan hasil penelitian yaitu : PT. Taman Wisata Candi Borobudur, Prambanan \& Ratu Boko (PT. TWC) telah memberikan dana CSRnya kepada Pemerintah Desa Borobudur untuk pembangunan Balkondes Borobudur, Pada design bangunan Balkondes Desa Borobudur telah tercantum identitas (corporate design) PT. Taman Wisata Candi Borobudur, Prambanan \& Ratu Boko (PT. TWC) selaku BUMN sponsor, dan sudah terdapat laporan penggunaan dana CSR untuk pelaksanaan kegiatan Balkondes Desa Borobudur.

c. Pendampingan dalam operasional Balkondes

Warung Kopi Borobudur

Pendampingan dalam operasional Balkondes Warung Kopi Borobudur dilakukan oleh BUMN Pendamping yaitu PT. PT. Taman wisata Candi Borobudur, Prambanan, dan Ratu Boko (PT. TWC) dan PT. Patra Jasa. Pada tahun 2016-2017 PT. Taman wisata Candi Borobudur, Prambanan, dan Ratu Boko (PT. TWC) melakukan pelatihan-pelatihan kepada masayarakat Desa Borobudur seperti pelatihan administrasi Balkondes dan homestay, pelatihan dalam pengelolaan Balkondes oleh tenaga ahli dari institusi ternama di Indonesia seperti Real In, Garuda Indonesia, dan Hotel Indonesia. Pada awal tahun 2018 dalam pendampingan PT. Patra Jasa terdapat sosialisasi terkait aktivasi Balkondes dan homestay. 
d. Operasional Balkondes Warung Kopi Borobudur oleh BUMDes

Pada tahap operasional Balkondes Warung Kopi Borobudur ini telah dilakukan oleh Pemerintah Desa Borobudur melalui BUMDes Mandala yang melibatkan 15 karyawan Balkondes dan bekerjasama dengan masyarakat desa seperti :

1) Ibu-ibu masyarakat Desa Borobudur, yaitu ibu-ibu penjual makanan yang mendirikan booth gerai makanan di halaman depan Balkondes, ibu-ibu PKK Desa Borobuduryang ikut berkontribusi untuk menjadi pemasok makanan saat ada event-event tertentu di Balkondes Warung Kopi Borobudur, dan ibu-ibu yang menitipkan makanan ringan di balkondes Warung Kopi Borobudur.

2) Paguyuban Art Shop Warung Kopi Borobudur, berkontribusi untuk mengumpulkan para pengarajin di Desa Borobudur supaya menitipkan hasil kerajinan seperti kerajinan batu, kerajinan kayu, kerajinan kain, kerajinan batik dan mainan-mainan untuk dijual di Art Shop Balkondes Warung Kopi Borobudur.

3) Karang Taruna, kerjasama hanya saat ada order atau request kegiatan saja. Contohnya seperti kegiatan melukis payung dan penyewaan sepeda/onthel.

Selain dengan masyarakat desa juga dalam Balkondes Warung Kopi Borobudur bekerja sama dengan Komunitas Andong Wisata "Tilik Ndeso". Dalam hal ini Balkondes Warung Kopi Borobudur masuk sebagai salah satu destinasi dalam rute perjalanan andong wisata "Tilik Ndeso". e. Pendampingan dalam pengelolaan Balkondes Warung Kopi Borobudur olehPT. Manajemen CBT Nusantara (PT.MCN)

Pada tahap pendampingan dalam pengelolaan Balkondes Warung Kopi Borobudur oleh PT. Manajemen CBT Nusantara (PT.MCN) ini, PT.MCN telah mempunyai berbagai program untuk pengembangan Balkondes bersama dengan BUMN sponsor, Pemerintah Desa, BUMDes dan masyarakat desa. Program Pendampingan Desa tersebut adalah standarisasi Balkondes dan homestay yang terdiri dari pendampingan dan pelatihan berupa hospitality, diferensiasi produk, bench marking, bahasa Inggris, administrasi keuangan, pengelolaan sosial media, dan leadership. Dalam pendampingan dan pelatihan tersebut juga dilaksanakan monitoring dan evaluasi berupa pertemuan rutin, evaluasi, dan pertemun incidental. Selain program standarisasi Balkondes dan homestay, ada juga program pengembangan potensi desa dalam pengembangan Balkondes. Akan tetapi program-program tersebut belum dirasakan sepenuhnya oleh Balkondes Warung Kopi Borobudur karena PT. Manajemen CBT Nusantara (PT.MCN) masih baru dan butuh proses dalam menjalankan semua program tersebut.

\section{Ukuran Keberhasilan Kolaborasi dalam Pengembangan Desa Wisata}

Keberhasilan kolaborasi yang dilakukan antar stakeholder dalam pengembangan desa wisata melalui Program Balai Ekonomi Desa (Balkondes) dapat dilihat yakni :

\section{a. Networked structure}

Model network administrative organization dalam kolaborasi disini dapat dilihat dari entitasadministratif yang telah diatur dalam perjanjian kerjasama dalam Program Balai Ekonomi Desa (Balkondes) Desa Borobudur atau Balkondes Warung Kopi Borobudur. Akan tetapi dalam perjanjian kerjasama tersebut hanya mengatur antara PT. Taman Wisata Candi Borobudur, Prambanan \& Ratu Boko (PT. TWC) selaku BUMN sponsor dan Pemerintah Desa Borobudur melalui BUMDes, belum menjelaskan terkait keterlibatan PT. Manajemen CBT Nusantara (PT. MCN) yang sekarang selaku pengelola Program Balkondes.

Terkait kedudukan antar stakeholder yang terlibat adalah sama, tidak ada satu pihak yang berkedudukan lebih tinggi dari pihak lainnya, hanya saja tugas dan fungsi tiap-tiap stakeholder berbeda.

\section{b. Commitment to a common purpose}

PT. Taman Wisata Candi Borobudur, Prambanan \& Ratu Boko (PT. TWC), PT. Manajemen CBT Nusantara (PT. MCN), Pemerintah Desa Borobudur, BUMDes Graha Mandala, dan karyawan Balkondes Borobudur sudah berkomitmen penuh terhadap Program 
Balai Ekonomi Desa (Balkondes) di Desa Borobudur. Wujud komitmen dari para stakeholder tersebut dibutikan dengan saling bahu membahu antar stakeholder untuk tercapainya tujuan dari adanya Program Balai Ekonomi Desa (Balkondes).

\section{c. Trust among the participants}

Sudah ada rasa saling percaya antar PT. Taman Wisata Candi Borobudur, Prambanan \& Ratu Boko (PT. TWC), PT. Manajemen CBT Nusantara (PT. MCN), Pemerintah Desa Borobudur, BUMDes Graha Mandala, karyawan balkondes dan masyarakat desa dalam melakukan tugasnya masing-masing sehingga diharapkan tujuan dari Program Balai Ekonomi Desa (Balkondes) dapat tercapai.

\section{d. Adanya kepastian governance}

1) Boundary dan exlusivity

Pada awalnya memang pihak- pihak yang berkolaborasi dalam Balkondes Borobudur ini sudah tercantum dalam perjanjian kerjasama. Akan tetapi seiring berjalannya waktu, terdapat stakeholder baru dalam Program Balkondes ini yaitu PT. Manajemen CBT Nusantara (PT. MCN) yang belum terlibat pada awal perjanjian kerjasama.

\section{2) Rules}

Dalam Program Balai Ekonomi Desa (Balkondes), operasional Balkondes Warung Kopi Borobudur mengacu pada SOP dari BUMDes Graha Mandala.

\section{3) Self determination}

Tidak ada batasan-batasan untuk Balkondes Desa Borobudur melakukan kerjsama dengan pihak lain, sejauh tidak melampaui batasan-batasan yang sudah disepakati antara BUMN sponsor dan Pemerintah Desa, yaitu antara PT. Taman Wisata Candi Borobudur, Prambanan \& Ratu Boko (PT. TWC) dan Pemerintah Desa Borobudur.

4) Network management

Ditunjukan dengan Balkondes Borobudur ini berjalan dengan baik, dimana tidak ada penolakan mengenai program inidan dengan jelas terdapat monitoring dan evaluasi baik secara internal melalui BUMDes Graha Mandala maupun secara eksternal melalui PT. Manajemen CBT Nusantara (PT. MCN) dan PT. Taman
Wisata Candi Borobudur, Prambanan \& Ratu Boko (PT. TWC).

\section{e. Access to authority}

Dalam Program Balai Ekonomi Desa (Balkondes) semua standar ukuran, serta prosedur mengenai otoritas didalam operasional Balkondes Warung Kopi Borobudur ini dipegang penuh oleh Karyawan Balkondes dan BUMDes yang bertanggung jawab kepada Pemerintah Desa.

\section{f. Distributive accountability/Responsibility}

Distributif Accountability/Responsibility (Pembagian Akuntabilitas/Responsibilitas) antar stakeholder sudah baik. Hal ini dapat dilihat dari para stakeholder yang telah melaksanakan tanggung jawabnya masing-masing dan adanya laporan pertanggungjawaban keuangan yang jelas. g. Information sharing

Kegiatan berbagi informasi berjalan melalui komunikasi yang baik antar stakeholder dan melalui pertemuan rutin atau incidental.

\section{h. Access to resources}

Ketersediaan sumber keuangan dalam Balkondes Warung Kopi Borobudur adalah dari BUMN sponsor yaitu PT. Taman Wisata Candi Borobudur, Prambanan \& Ratu Boko (PT. TWC) dan dibantu oleh PT. Manajemen CBT Nusantara (PT. MCN) dan untuk sumber daya manusia dalam Balkondes Desa Borobudur ini adalah warga atau masyarakat Desa Borobudur itu sendiri.

\section{SIMPULAN}

Efektivitas kolaborasi dalam program Balai Ekonomi Desa(Balkondes) di Desa Borobudur atau Balkondes Warung Kopi Borobudur adalah dari semua indikator keberhasilan kolaborasi menurut DeSave yang meliputi : (1) Networked structure, (2) Commitment to a common purpose, (3) Trust among the participants, (4) Governance, (5) Access to authority, (6) Distributive accountability/responsibility, (7) Information sharing, dan (8) Access to resources, sudah berjalan dengan baik. Hanya saja terkait entitas administratif dalam perjanjian kerjasama hanya mengatur antara PT. Taman Wisata Candi Borobudur, Prambanan \& Ratu Boko (PT. TWC) selaku BUMN pendamping 
dan sponsor, dan Pemerintah Desa Borobudur melalui BUMDes, belum menjelaskan terkait keterlibatan PT. Manajemen CBT Nusantara (PT. MCN) yang sekarang selaku pengelola Program Balkondes. Sehingga boundary dan exclusivity dalam governance belum menyebutkan semua pihak yang terlibat dalam kolaborasi.

\section{DAFTAR RUJUKAN}

Ansell, C., \& Gash, A. 2007. Collaborative Governance in Theory and Prctice. Journal of Public Administration Research and Theory, 1-30.

Demartoto, A. 2009. Pembangunan Pariwisata Berbasis Masyarakat. Surakarta: Sebelas Maret University Press.

Emerson, K., Nabatchi, T., \& Balogh, S. 2011. An Integrative Framework for Collaborative
Governance. Journal of Public Administration Research and Theory.

Kurniawan, S. 2017. Mengembangkan Ekonomi Kerakyatan Lewat Balkondes. https:// www.antarafoto.com/foto-cerita/ v $1513314033 /$ mengembangkanekonomi-kerakyatan-lewat- balkondes.

Peraturan Menteri Badan Usaha Milik Negara Nomor PER-09/MBU/07/2015 tentang Program Kemitraan dan Program Bina Lingkungan Badan Usaha Milik Negara

Sudarmo. 2011. Isu-Isu Administrasi Publik dalam Perspektif Governance. Surakarta: Smart Media.

Winasis, A., \& Setyawan, D. 2016. Efektivitas Program pengembangan Desa Wisata Melalui Kelembagaan Dalam Peningkatan Sumber Daya Alam (SDA). JISIP: Jurnal Ilmu Sosial dan Ilmu Politik, Vol. 5, No. 2. 